\title{
Hubungan Tata Guna Lahan Terhadap Infiltrasi (Studi Kasus : Kawasan Perkantoran Walikota Bukittinggi)
}

\author{
Deddy Kurniawan \\ Fakultas Teknik, Universitas Muhammadiyah Sumatera Barat \\ email: deddydk22@gmail.com
}

\begin{abstract}
Pertumbuhan penduduk kota Bukittinggi sangat pesat. Berdasarkan data statistik pada tahun 2004, jumlah penduduk kota Bukittinggi mencapai 120.491 jiwa dengan laju pertumbuhan penduduk selama kurun waktu 2015 sampai 2016 sebesar 1,82 persen. Seiring dengan peningkatan jumlah penduduk ini, maka mengakibatkan kebutuhan akan lahan juga meningkat. Lahan - lahan yang tadinya oleh alam sebagai daerah resapan atau daerah infiltrasi berubah fungsi menjadi wilayah administrasi, area parkir, pasar dan wilayah lain yang bersifat kedap air. Hal inilah yang menjadi awal terjadinya aliran permukaan yang pada kondisi selanjutnya akan berubah menjadi banjir di suatu kawasan. Maka pada kasus ini penulis mencoba melakukan suatu penelitian yang berlokasi di bukit gulai bancah ( Perkantoran Walikota). Pada studi ini penulis mempelajari seberapa luas daerah resapan, daerah yang tertutup bahan kedap air, aliran permukaan pada waktu terjadinya hujan dan apakah aliran permukaan itu akan dapat diserap oleh tanah seluruhnya atau bahkan hanya sebagiannya saja. Dari penelitian yang sudah dilakukan dapat diketahui bahwa luas keseluruhan bukit gulai bancah adalah $55.054 \mathrm{~m}^{2}$, dengan luas lahan yang dibangun dan lahan kedap air 26.606,5 $\mathrm{m}^{2}$ dan dapat dipersentasekan luas lahan kosong atau media infiltrasi sebesar 28.447,5 $\mathrm{m}^{2}$ atau $51 \%$. Jumlah ini masih mengakibatkan adanya kelebihan aliran permukaan sebesar $386,32 \mathrm{~mm} / \mathrm{jam}$. Problem ini dapat diatasi dengan melakukan perbaikan-perbaikan tata guna lahan, drainase, atau pembuatan bak penampungan, sumur resapan serta penanaman tanamam yang dapat menyimpan dan menyerap air.
\end{abstract}

Keywords: Infiltrasi, aliran permukaan, daerah resapan

\begin{abstract}
Population growth the city of Bukittinggi very rapidly. Based on statistical data on the year 2004, the total population of the city of Bukittinggi reach 120.49133 soul with the rate of population growth during the period 2015 to 2016 of 1,82 percent. Along with the increase in population, resulting in the need for land also increases. Land - land that had been by nature as the pervasive infiltration area or changed functionality into the administration area, parking area, market and other areas which are impermeable to water. This became the beginning of the occurrence of a surface flow at the next condition will turn into a flood in a region. Then in this case the author trying to do a research that is located on the Hill of Coconut Curry bancah (the Mayor's Office). In this study the authors study how widespread the region of pervasive, the covered area material impermeable to water, surface flow at the time of the onset of the rain and whether the surface flow it will be absorbed by the ground entirely or even only in part only. From the research that's been done could note that the total area of the Hill bancah is the goulash 55,054 $\mathrm{m}^{2}$ in size, with an area of land that is being built and land 26,606.5 $\mathrm{m}^{2}$ of water-proof and can be percentage land area is empty or media infiltration of $28,447.5 \mathrm{~m}^{2}$ or $51 \%$. This number still resulted in the presence of excess surface flow of $386.32 \mathrm{~mm} / \mathrm{hour}$. This problem can be overcome by doing improvements, drainage, land use, or manufacture of a tub soak wells as well as shelter, planting crops that can hold and absorb water.
\end{abstract}

Keywords: Infiltration, surface flow, the pervasive 


\section{PENDAHULUAN}

Setiap daerah sudah memiliki Rencana Tata Ruang dan Wilayah, nampaknya pengawasan terhadap ketentuan tersebut seringkali tak berjalan dengan baik, dan tampak disana-sini terjadi modifikasi yang mengakibatkan penutupan lahan menjadi makin luas, yang mengakibatkan aliran permukaan bertambah kuantitasnya.

Tingkat urbanisasi yang tinggi di kota-kota besar semakin menambah penutupan lahan karma dibangunnya perumahan dan selanjutnya mengurangi daerah resapan air, dengan adanya penutupan lahan akibat peningkatan pemukiman yang tidak terkendali, berpengaruh terhadap besaran aliran permukaan berakibat meluasnya genangan dan tambahan debit di saluran pembuang. Selanjutnya berakibat buruk terhadap lingkungan.

Menurut Peraturan Pemerintah RI no. 69 tahun 1996 kawasan kota merupakan suatu kawasan yang mempunyai kegiatan utama bukan pertanian, tetapi fungsi kawasan sebagai tempat permukiman perkotaan, pemusatan dan distribusi pelayanan jasa pemerintahan, pelayanan sosial dan kegiatan perekonomian. Definisi itu menggambarkan fungsi kota yang disertai dengan berbagai fasilitasnya dan merupakan kawasan yang dicirikan dengan adanya bangunan sebagai tempat permukiman dan berbagai fasilitas pelayanan.

Padatnya bangunan menyebabkan semakin luasnya penutupan tanah sehingga berakibat pada ketidak-seimbangan lingkungan, misalnya proses-proses yang melibatkan pergerakan air seperti limpasan permukaan, erosi dan resapan air kedalam tanah. Limpasan permukaan yang terjadi pada saat hujan meningkat karena berkurangnya peresapan akibat bertambahnya luas bangunan yang menutupi permukaan tanah.

Berfungsinya peresapan air kedalam tanah dipengaruhi oleh sifat-sifat hujan, sifat fisik kawasan dan pengelolaannya. Pengalihan fungsi lahan di perkotaan cenderung ke arah penutupan tanah dengan bahan-bahan semen yang tidak tembus air (impervious), sehingga mengakibatkan terganggunya keseimbangan hidrologi. Hidrologi kota seringkali menjadi masalah yang pelik bagi ahli hidrologi, karena urbanisasi meningkatkan luasan permukaan yang tertutup semen, paving, aspal, sehingga air hujan tercegah untuk masuk ke dalam tanah dan menjadi limpasan permukaan (Urbanos, 1992).

Penelitian ini mengkaji peresapan air kedalam tanah / infiltrasi akibat perubahan penggunaan atau tata guna lahan dari daerah resapan ke daerah pengembangan di bukit gulai bancah Bukittinggi, tepatnya pada lokasi perkantoran walikota Bukittinggi.

\section{METODE PENELITIAN}

Data Curah Hujan ( $\mathrm{CH}$ ) 30 menitan kota bukittinggi dianalisis menjadi Intensitas Curah Hujan ( $\mathrm{ICH}$ ) dengan periode ulang 5,10 , dan 25 tahun. Menggunakan teori Chow dkk, dianalisis aliran permukaan yang terjadi pada tiga jenis tanah, yang menyertakan intensitas curah hujan, infiltrasi dan panjang lahan searah aliran, dengan kemiringan lahan yang bersudut $00,30,50,100$, dan 150 . Tiga jenis tanah tersebut adalah Lempung berliat, lempung, dan pasir berlempung, dengan sebagian bahan penutup lahan kedap air.

Aliran di atas permukaan lahan menurut uraian tersebut diatas dapat dilihat pada gambar berikut

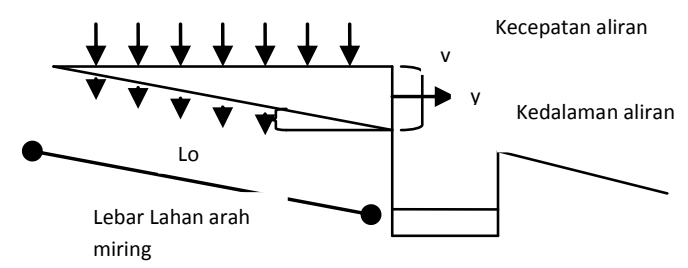

\section{LOKASI PENELITIAN}

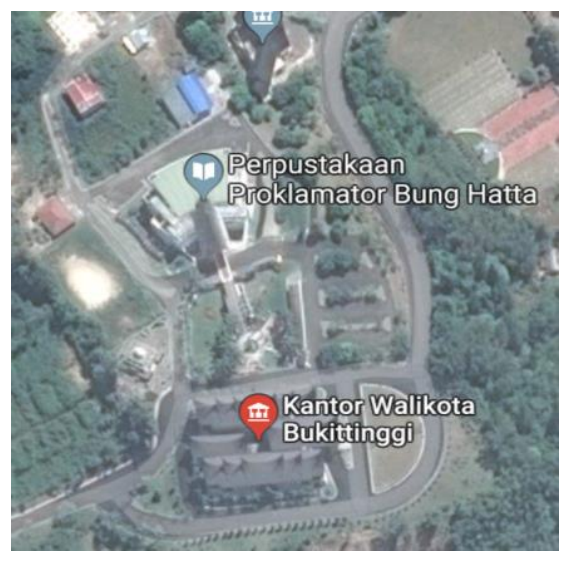

Bilangan Reynold 
Aliran air yang melalui suatu permukaan peril ditelaah keadaan alirannya, agar diperoleh gambaran perilaku aliran terhadap butiran-butiran pembentuk permukaan lahan. Telaah dilakukan dengan menggunakan teori yang disampaikan oleh Low and yen dan atau emmet, Untuk memenuhi kriteria apakah aliran tersebut turbulen atau laminar. Analisis yang memberikan gambaran keadaan aliran tersebut mengikuti besaran bilangan Reynold ( $\mathrm{Re}$ ), aliran turbulen dengan nilai $\mathrm{Re}>2000$ dan aliran laminer nilai $\operatorname{Re} \leq 2000$.

$\mathrm{Re}=\frac{4 \mathrm{go}}{V}$

Keterangan :

Re $=$ Bilangan Reynold

$\mathrm{q} 0=$ Debit aliran per satuan lebar $(\mathrm{m} 2 / \mathrm{s})$

$\mathrm{v}=$ Viskositas air $(\mathrm{m} 2 / \mathrm{s})$

\begin{tabular}{|c|c|}
\hline $\begin{array}{c}\text { Suhu } \\
{ }^{0} \mathrm{C}\end{array}$ & Viskositas $\left(\mathrm{m}^{2} / \mathrm{s}\right)$ \\
\hline 15.6 & 0.131 \\
\hline 21.1 & 0.112 \\
\hline 26.7 & 0.0974 \\
\hline 32.2 & 0.0763 \\
\hline
\end{tabular}

\section{HASIL DAN PEMBAHASAN}

Kapasitas infiltrasi berbagai jenis tanah dapat kita lihat pada tabel berikut :

Tabel 3.1 Data kapasitas infiltrasi dari beberapa tipe tanah

\begin{tabular}{|c|l|c|c|}
\hline \multirow{2}{*}{ No } & \multicolumn{1}{|c|}{ Tekstur tanah } & \multicolumn{2}{|c|}{$\begin{array}{c}\text { Kapasitas infiltrasi } \\
\text { (mm/jam ) }\end{array}$} \\
\cline { 3 - 4 } & & $\mathrm{f}$ & $\mathrm{f}$ rata- \\
\hline 1. & Pasir berlempung (Loamy sand) & $25-50$ & 37,5 \\
\hline 2. & Lempung (Loam) & $12,5-25$ & 18,75 \\
\hline 3. & Lempung berliat (Clay loam) & $0,5-2,5$ & 1,50 \\
\hline
\end{tabular}
Sipil

Sumber : Media Komunikasi Teknik

Memperhatikan tabel diatas dapat diketahui bahwa jenis tanah pasir berlempung mempunyai kapasitas infiltrasi yang cukup tinggi

\section{ANALISA DATA CURAH HUJAN}

Perhitungan curah hujan dilakukan dengan cara analitis, dimana harga-harga $\mathrm{Y}_{\mathrm{T}}$, $\mathrm{Y}_{\mathrm{N}}$, dan $\mathrm{S}_{\mathrm{N}}$ dapat dilihat pada tabel. Berdasarkan rumus maka dapat diperhitungkan harga curah hujan harian maksimum dengan periode ulang tertentu dengan memasukkan harga-harga variable yang diperhitungkan dan dapat dilihat pada tabel berikut :

\begin{tabular}{|c|c|c|c|c|}
\hline Tahun & $\begin{array}{c}\mathrm{X}_{1} \mathrm{~mm} / 24 \\
\text { jam }\end{array}$ & $\mathrm{M}$ & $\begin{array}{c}\left(\mathrm{X}_{1}-\right. \\
\mathrm{X})\end{array}$ & $\left(\mathrm{X}_{1}-\mathrm{X}\right)^{2}$ \\
\hline 2008 & 563 & 1 & 70,05 & 4970,25 \\
2009 & 412 & 2 & $-80,5$ & 6480,25 \\
2010 & 453 & 3 & $-39,5$ & 1560,25 \\
2011 & 550 & 4 & 57,5 & 3306,25 \\
2012 & 418 & 5 & $-74,5$ & 5550,25 \\
2013 & 329 & 6 & - & 26732,25 \\
2014 & 493 & 7 & 163,5 & 0,25 \\
2015 & 372 & 8 & 0,5 & 14520,25 \\
2016 & 618 & 9 & - & 15750,25 \\
2017 & 539 & 10 & 120,5 & 2162,25 \\
& & & 125,5 & \\
& & & 46,5 & \\
\hline & 4.925 & & & $81.030,5$ \\
\hline
\end{tabular}

Sumber : Analisa data

Tabel 3-3. Hasil perhitungan curah hujan harian maksimum sesuai dengan periode ulang menggunakan metode gumbel

\begin{tabular}{|c|r|}
\hline $\begin{array}{l}\text { Periode ulang } \\
\text { (tahun ) }\end{array}$ & $\begin{array}{l}\text { Curah hujan } \\
\text { maksimum } \\
\text { (mm/hari) }\end{array}$ \\
\hline 2 & 480,30 \\
5 & 587,74 \\
10 & 658,87 \\
25 & 748,77 \\
\hline
\end{tabular}

Sumber : Analisa Data

\section{KEADAAN \\ DIANALISIS}

LAHAN

YANG

Lahan yang dianalisis memiliki jenis tanah lempung berliat, dengan luas lahan sebesar $5,5 \mathrm{Ha}$ yang terbagi atas luas lahan yang boleh dibangun sudah termasuk untuk lahan parkir dan penutup lapisan kedap air.

Berikut adalah tabel keadaan lahan yang dianalisa. 
Tabel 3-4 Keadaan lahan yang dianalisa

\begin{tabular}{|l|l|l|l|l|}
\hline No & $\begin{array}{l}\text { Luas } \\
\text { Wilaya } \\
\text { h } \\
\left(\mathbf{~ m}^{\mathbf{2}}\right)\end{array}$ & $\begin{array}{l}\text { Kondisi } \\
\text { lahan }\end{array}$ & Bahan & $\begin{array}{l}\text { Luas } \\
\text { yang } \\
\text { Dibangu } \\
\text { n } \\
\left.\mathbf{~ m}^{\mathbf{2}}\right)\end{array}$ \\
\hline 1. & \multirow{2}{*}{55.054} & $\begin{array}{l}\text { Banguna } \\
\text { n } \\
\text { LahanPar } \\
\text { kir + } \\
3 .\end{array}$ & $\begin{array}{l}\text { Beton } \\
\text { Aspal }\end{array}$ & $\begin{array}{l}5.163,5 \\
16.672\end{array}$ \\
4. & & $\begin{array}{l}\text { Kedap air } \\
\text { Jalan } \\
\text { Taman }\end{array}$ & $\begin{array}{l}\text { Aspal } \\
\text { Rumpu } \\
\text { t }\end{array}$ & $\begin{array}{l}4.771 \\
11.910,4\end{array}$ \\
\hline \multicolumn{3}{|c|}{ Jumlah } \\
\hline
\end{tabular}

Sumber : Pengukuran di lapangan

Dari tabel diatas diketahui luas daerah yang dipenuhi oleh bangunan, jalan, parkir dan lahan yang kedap air 26.606,5 $\mathbf{m}^{2}$, sedangkan luas daerah keseluruhannya $\mathbf{5 5 . 0 5 4} \mathbf{~ m}^{2}$.

Jadi luas lahan kosong ditambah taman sebesar 28.447,5 $\mathbf{~ m}^{2}(51 \%)$

( Taman dikelompokan sebagai media infiltrasi )

\section{ANALISA KEADAAN TANAH}

Jenis tanah yang terdapat pada bukit Gulai Bancah adalah jenis tanah Lempung Berliat. Untuk debit aliran pada tanah ini dapat dilihat pada tabel dibawah ini :

Tabel 3.5 Debit aliran permukaan pada tanah lempung berliat

\begin{tabular}{|c|c|c|c|c|c|c|}
\hline \multirow[t]{2}{*}{ Jenis Tanah } & \multirow[t]{2}{*}{$\begin{array}{c}\mathrm{T} \\
\text { (tahun) }\end{array}$} & \multirow[t]{2}{*}{$\begin{array}{c}\mathrm{I} \\
\mathrm{mm} / \mathrm{jam}\end{array}$} & \multirow[t]{2}{*}{$\theta$} & \multirow[t]{2}{*}{ So } & \multicolumn{2}{|c|}{$\begin{array}{c}\mathrm{Q} \\
(\mathrm{It} / \mathrm{s})\end{array}$} \\
\hline & & & & & $\begin{array}{l}60 \% \\
\%\end{array}$ & +20 \\
\hline \multirow{12}{*}{ 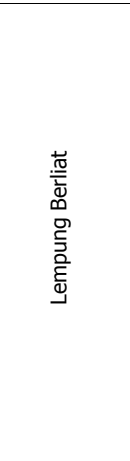 } & 5 & 57.4 & \multirow{3}{*}{0.3} & \multirow{3}{*}{0.00524} & 15.78 & 15.86 \\
\hline & 10 & 64.95 & & & 17.88 & 17.96 \\
\hline & 25 & 74.8 & & & 20.61 & 20.69 \\
\hline & 5 & 57.4 & \multirow{3}{*}{5} & \multirow{3}{*}{0.0875} & 15.71 & 15.80 \\
\hline & 10 & 64.95 & & & 17.81 & 17.89 \\
\hline & 25 & 74.8 & & & 20.53 & 20.61 \\
\hline & 5 & 57.4 & \multirow{3}{*}{10} & \multirow{3}{*}{0.17634} & 15.53 & 15.61 \\
\hline & 10 & 64.95 & & & 17.20 & 17.67 \\
\hline & 25 & 74.8 & & & 20.23 & 20.36 \\
\hline & 5 & 57.4 & \multirow{3}{*}{15} & \multirow{3}{*}{0.268} & 15.24 & 15.32 \\
\hline & 10 & 64.95 & & & 17.27 & 17.35 \\
\hline & 25 & 74.8 & & & 19.91 & 19.99 \\
\hline
\end{tabular}

Sumber : Media Komunikasi Teknik sipil volume 13, no 1, edisi XXXI Feb 2005
Tabel 3.6 Debit aliran pada tanah lempung

\begin{tabular}{|c|c|c|c|c|c|c|}
\hline \multirow[t]{2}{*}{ Jenis Tanah } & \multirow[t]{2}{*}{$\begin{array}{c}\mathrm{T} \\
\text { (tahun) }\end{array}$} & \multirow[t]{2}{*}{$\begin{array}{c}\mathrm{I} \\
\mathrm{mm} / \mathrm{jam}\end{array}$} & \multirow[t]{2}{*}{$\theta$} & \multirow[t]{2}{*}{ So } & \multicolumn{2}{|r|}{$\underset{(I t / s)}{Q}$} \\
\hline & & & & & $20 \%$ & $20 \%+20 \%$ \\
\hline \multirow{12}{*}{ 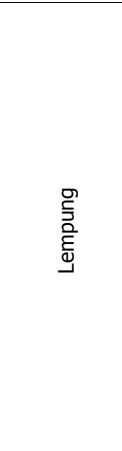 } & 5 & 57.4 & \multirow{3}{*}{0.3} & \multirow{3}{*}{0.00524} & 11,78 & 12,82 \\
\hline & 10 & 64.95 & & & 13,88 & 14,92 \\
\hline & 25 & 74.8 & & & 16,61 & 21,81 \\
\hline & 5 & 57.4 & \multirow{3}{*}{5} & \multirow{3}{*}{0.0875} & 11,73 & 12,77 \\
\hline & 10 & 64.95 & & & 13,82 & 14,86 \\
\hline & 25 & 74.8 & & & 16,54 & 17,58 \\
\hline & 5 & 57.4 & \multirow{3}{*}{10} & \multirow{3}{*}{0.17634} & 11,59 & 12,61 \\
\hline & 10 & 64.95 & & & 13,65 & 14,68 \\
\hline & 25 & 74.8 & & & 16,35 & 17,37 \\
\hline & 5 & 57.4 & \multirow{3}{*}{15} & \multirow{3}{*}{0.268} & 11,38 & 12,38 \\
\hline & 10 & 64.95 & & & 15,42 & 16,42 \\
\hline & 25 & 74.8 & & & 16,05 & 17,05 \\
\hline
\end{tabular}

Sumber : Media Komunikasi Teknik sipil volume 13, no 1, edisi XXXI Feb 2005

Tabel 3.7 Aliran Permukaan pada tanah pasir berlempung

\begin{tabular}{|c|c|c|c|c|c|c|}
\hline \multirow[t]{2}{*}{ Jenis Tanah } & \multirow[t]{2}{*}{$\begin{array}{c}\mathrm{T} \\
\text { (tahun) }\end{array}$} & \multirow[t]{2}{*}{$\begin{array}{c}\mathrm{I} \\
\mathrm{mm} / \mathrm{jam}\end{array}$} & \multirow[t]{2}{*}{$\theta$} & \multirow[t]{2}{*}{$\mathrm{S}_{0}$} & \multicolumn{2}{|r|}{$\begin{array}{c}Q \\
(I t / s)\end{array}$} \\
\hline & & & & & $10 \%$ & $10 \%+20 \%$ \\
\hline \multirow{12}{*}{ 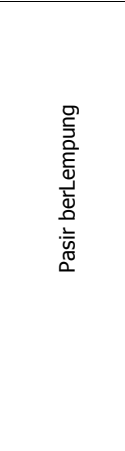 } & 5 & 57.4 & \multirow{3}{*}{0.3} & \multirow{3}{*}{0.00524} & 6,57 & 8,65 \\
\hline & 10 & 64.95 & & & 8,67 & 10,75 \\
\hline & 25 & 74.8 & & & 11,40 & 13,49 \\
\hline & 5 & 57.4 & \multirow{3}{*}{5} & \multirow{3}{*}{0.0875} & 6,54 & 8,62 \\
\hline & 10 & 64.95 & & & 8,63 & 10,71 \\
\hline & 25 & 74.8 & & & 11,36 & 13,43 \\
\hline & 5 & 57.4 & \multirow{3}{*}{10} & \multirow{3}{*}{0.17634} & 6,46 & 8,51 \\
\hline & 10 & 64.95 & & & 8,53 & 10,58 \\
\hline & 25 & 74.8 & & & 11,22 & 13,27 \\
\hline & 5 & 57.4 & \multirow{3}{*}{15} & \multirow{3}{*}{0.268} & 6,35 & 8,36 \\
\hline & 10 & 64.95 & & & 8,37 & 10,38 \\
\hline & 25 & 74.8 & & & 11,02 & 13,03 \\
\hline
\end{tabular}

Sumber : Media Komunikasi Teknik sipil volume 13, no 1, edisi XXXI Feb 2005

Keterangan :

$\begin{array}{ll}\mathrm{T} & : \text { Tahun Pengamatan } \\ \mathrm{I} & : \text { Intensitas hujan } \\ \theta & : \text { Sudut kemiringan lahan } \\ \mathrm{S}_{\mathrm{o}} & : \text { Kemiringan lahan } \\ \mathrm{Q} & : \text { Debit aliran }\end{array}$

\section{PERHITUNGAN KAPASITAS}

INFILTRASI

- Luas lahan keseluruhan $=55.054 \mathrm{~m}^{2}$

- Luas lahan yang tertutup = $26.606,5 \mathrm{~m}^{2}$

- Luas lahan terbuka $(\beta A)=$ $28.447,5 \mathrm{~m}^{2}$ 
- Curah hujan maksimum $(\mathrm{H}) \quad=$ $31,198 \mathrm{~mm} / \mathrm{jam}$

- Kapasitas infiltrasi lahan (c) = $1,50 \mathrm{~mm} / \mathrm{jam}$ ( Lempung berliat )

Jumlah debit aliran yang terjadi :

$=$ Curah hujan maksimum $x$ Luas lahan keseluruhan

$$
\begin{array}{cc}
= & 31,198 \times 55.054 / 1000 \\
= & 1717,57 \mathrm{~mm} / \mathrm{jam}
\end{array}
$$

Jumlah debit aliran yang diserap tanah :

$$
I=c H(\beta A) / 1000
$$

$=\quad 1.50 \times 31.198 \times 28.447,5 /$ 1000

Kelebihan debit aliran :

$$
=\quad 1331.25 \mathrm{~mm} / \mathrm{jam}
$$

terjadi - Jumlah debit aliran yang terjadi

$$
\begin{array}{ll}
= & 1717,57-1331,25 \\
= & 386,32 \mathrm{~mm} / \mathrm{jam}
\end{array}
$$

Jumlah debit aliran permukaan tersebut adalah jumlah debit aliran yang tidak dapat di serap oleh tanah

\section{SIMPULAN}

1. Jumlah debit aliran permukaan yang terjadi pada lokasi bukit gulai bancah Bukittinggi adalah 386,32 mm/jam

2. Penurunan jumlah peresapan air / kapasitas infiltrasi yang terjadi di perbukitan kantor walikota Bukittinggi kecil ( $1,50 \mathrm{~mm} / \mathrm{jam})$ karna jenis tanahnya lempung berliat.

3. Building Coverage Ratio( $\mathrm{BCR}$ ) di lokasi perbukitan kantor walikota masih berada di atas persentase penutupan lahan yang diizinkan yaitu $51 \%$.

\section{SARAN}

1. Untuk menjaga agar keseimbangan lingkungan kawasan bukit gulai bancah stabil, maka perlu dilaksanakan penghijauan yang dapat menyerap air dengan tujuan mempertahankan tinggi muka air tanah.

2. Pengendalian debit aliran permukaan yang tidak dapat diserap oleh tanah dapat diatasi dengan membuat bak penampungan atau sumur resapan atau penanaman tanaman yang dapat menyerap dan menyimpan air.

3. Penutupan lahan dengan bahan kedap air di lokasi dapat diimbangi dengan taman
- taman yang sangat berperan sebagai media infiltrasi.

\section{UCAPAN TERIMAKASIH}

Puji syukur penyusun panjatkan kehadapan Allah SWT, karena atas berkat, rahmat dan bimbingan-NYA penyusun dapat menyelesaikan jurnal ilmiah yang berjudul “ Hubungan Tata Guna Lahan Dan Infiltrasi (Studi Kasus : Kawasan Perkantoran Walikota Kota Bukittinggi) “. Tersusunnya Jurnal Ilmiah ini tentunya tidakterlepas dari bantuan banyak pihak dalammemberikan bimbingan, pengarahan, petunjuk,bantuan, informasi dan berbagai bantuan lainnya.Untuk itu melalui kesempatan ini penyusunmengucapkan terima kasih kepada, orang tua, keluarga, teman-teman yang saling mendukung danmembantu menyelesaikan Jurnal Ilmiah ini.

\section{DAFTAR PUSTAKA}

Anwar A. 1993. Dampak Alih Fungsi Lahan sawah Menjadi Lahan Non-Pertanian Di

Sekitar Wilayah Perkotaan. Jurnal Perencanaan Wilayah dan Kota Nomor 10, Triwulan IV. Bandung.

Arsyad S. 1989. Konservasi Tanah dan Air [skripsi]. Bogor: Jurusan Tanah, FakultasPertanian, Institut Pertanian Bogor. Bogor.

BAPEDA, Rencana Detail Tata Ruang (RDTR) Kota Bukittinggi 2016 - 2021

Badan Pusat Statistik ( BPS), Keadaan geografi, penduduk dan angkatan kerja Bukittinggi dalam angka 2016

Bisri, Mohammad, 2008, Konservasi Air Dalam Perencanaan Ruang, Malang :Penerbit Tirta Media

Fauzi, A, 2004; Ekonomi Sumber daya Alam dan Lingkungan, Gramedia

Hadhisiswoyo, S (1998), Tinjauan Tentang Aliran Air Hujan Pada beberapa Tipe Rumah, Jurnal Teknik Sipil dan Arsitektur, No 1-1998, Bandung

Jayadinata, J.T, ; Tata Guna Tanah Dalam Perencanaan Pedesaan , Perkotaan \&Wilayah, Edisi Ketiga, Penerbit ITB Bandung. 
Linsley,R.K, Kohler,M.A, Paulhus, J.H, 1988; Hydrology for Engineers, Mc GrawHill Book Company.

MEDIA KOMUNIKASI TEKNIK SIPIL, Volume 13, no 1, edisi XXXI februari 2005

Muif, M, 1991 : Pengaruh Eksploitasi Air Tanah Terhadap Sistem KeseimbanganTata Air di Wilayah Jakarta (Tesis), Program Pasca Sarjana, IPB

Peraturan Pemerintah RI no. 69 tahun 1996 tentang kawasan kota

Sahidin D. 1995. Kajian Alih Fungsi Lahan Akibat Perkembangan Industri diKabupaten Daerah Tingkat II Purwakarta, Jawa Barat. Tesis. ProgramPascasarjana. Jurusan Teknik Planologi. ITB. Bandung.

Soepardi G. 1977. Sifat dan Ciri Tanah. IPB Press. Bogor.

Somaji PR. 1994. Perubahan Tata Guna Lahan dan Dampaknya TerhadapMasyarakat Petani di Jawa Timur. [tesis]. Bogor: Program Pascasarjana PWD,Institut Pertanian Bogor. Bogor.

Suripin. 2003. Pelestarian Sumberdaya Tanahdan Air. Andi : Jogjakarta

Undang - undang Nomor 7 Tahun 2004 tentangSumber Daya Air

Undang - undang Nomor 26 Tahun 2007 tentangPenataan Ruang

Yunus, H.S, 2001 ; Struktur Tata Ruang Kota, Pustaka Pelajar 